\title{
What Are the Potential Predictors of Psychological Capital for Chinese Primary School Teachers?
}

\author{
Xinjie Chen ${ }^{1}$, Guang Zeng ${ }^{2 \star}$, Edward C. Chang ${ }^{3}$ and Hoi Yan Cheung ${ }^{4}$ \\ ${ }^{1}$ Graduate School of Education, Stanford University, Stanford, CA, United States, ${ }^{2}$ Department of Psychology, Tsinghua \\ University, Beijing, China, ${ }^{3}$ Department of Psychology, University of Michigan, Ann Arbor, MI, United States, ${ }^{4}$ Faculty of \\ Education, University of Macau, Macau, China
}

OPEN ACCESS

Edited by:

Claudio Longobardi,

University of Turin, Italy

Reviewed by:

Dingguo Gao,

Sun Yat-sen University, China

Shenlong Yang

Xi'an Jiaotong University, China

${ }^{*}$ Correspondence:

Guang Zeng

zengguang0118@163.com

Specialty section:

This article was submitted to

Educational Psychology,

a section of the journal

Frontiers in Education

Received: 25 January 2019

Accepted: 17 May 2019

Published: 11 June 2019

Citation:

Chen X, Zeng G, Chang EC and

Cheung HY (2019) What Are the

Potential Predictors of Psychological Capital for Chinese Primary School

Teachers? Front. Educ. 4:50.

doi: 10.3389/feduc.2019.00050
This study aimed to explore the cognitive and affective factors that predict the Psychological capital (PsyCap) of Chinese primary school teachers. The participants were 1,384 teachers from 34 primary schools in Chengdu city, in southwestern part of China. A resource model of PsyCap was proposed and tested using structural equation modeling (SEM). The model was tested with two independent variables of growth mindset and well-being as predictors of PsyCap. Results showed that both cognitive construct (i.e., growth mindset) and affective construct (i.e., well-being) were positively and significantly related to the PsyCap. In addition, SEM results indicated a significant influence of both growth mindset and well-being on all the variables of PsyCap (i.e., Efficacy, Hope, Optimism, and Resilience). Explanations and implications were discussed for the findings, and some limitations were also discussed.

Keywords: Chinese, primary school teachers, growth mindset, well-being, psychological capital (PsyCap), positive psychology

\section{INTRODUCTION}

Psychological capital (PsyCap) refers to one's positive psychological state of development and consists four personal qualities: self-efficacy, optimism, hope, and resiliency (Luthans et al., 2007b). There has been substantial evidence showing that PsyCap is positively related to a number of beneficial outcomes, such as job satisfaction, health, and psychological well-being (Avey et al., 2011; Cassidy et al., 2014), and is negatively related to several undesirable outcomes, such as job stress and anxiety (Avey et al., 2011). Although PsyCap is considered as an important and positive resource for personal development, very little research has tried to examine for the potential factors that might promote PsyCap. In the present study, we explore the potential predictors of PsyCap among primary school teachers in China, where teachers' burnout, stress, and dissatisfaction are becoming growing concerns (Chan, 2003) due to the large classes, limited educational resources, heavy workload and low level of reward (Tang et al., 2001).

\section{Psychological Capital}

The concept of PsyCap is based on theory and research derived from positive psychology. Seligman and Csikszentmihalyi (2000) argued that traditional psychology focused mainly on mental illnesses and pathologies, and proposed positive psychology. Positive psychology focuses on making people's lives more productive and worthwhile and helping them actualize their potential as individuals (Luthans and Youssef, 2004). Extended positive psychology to organizational studies, Luthans (2002) proposed positive organizational behavior (POB), defined as "the study and application of positively oriented human resource strengths and psychological capacities" (p. 59). Positive 
organizational behavior focused on enhancing people's resource strengths and psychological capacities in a measurable way so that the performance of individuals at the workplace can be improved. Efficacy, hope, optimism and resiliency are included as the capacities of positive organizational behavior, and they are also known as the foundation of positive PsyCap (Luthans and Youssef, 2004). PsyCap is "characterized by: (a) having confidence (self-efficacy) to take on and put in the necessary efforts to succeed at challenging task; (b) making a positive attribution (optimism) about succeeding now and in the future; (c) persevering toward goals and, when necessary, redirecting paths to goals (hope) in order to succeed; and (d) when beset by problems and even beyond (resilience) to attain success" (Luthans et al., 2007b, p.3). The four variables (efficacy, hope, optimism and resiliency) that made up PsyCap are unique, measurable, developable, and impactful on performance (Luthans et al., 2004). Luthans et al. (2004) also mentioned that in the past, the business field paid full attention on the traditional economic capital (e.g., finances and tangible assets). However, businessmen found that this is not sufficient. Thus, they later paid more attention to other capitals, such as the human capital (experience, education, skills, knowledge, and ideas) and social capital (relationships, network of contacts, and friends). In recent years, businessmen found that the four variables in positive PsyCap are also very important for business and economic growth (Luthans et al., 2004, 2007a; Rego et al., 2012).

There have been a number of studies investigating the impact of PsyCap on adjustment. For example, Luthans et al. (2007a) found that when the four variables of PsyCap were separated or combined, they could significantly predict employees' work performance and satisfaction. As mentioned, individuals having high PsyCap can enhance business and economic growth. This belief was strengthened by Luthans et al. (2006) that when participants' PsyCap was enhanced through training, there were positive impacts on the companies' financial and investment profits. There are many advantages for individuals to have high PsyCap in general. Luthans et al. (2008b) indicated that when employees have high scores in their efficacy, hope, optimism and resiliency, they also found high performance, satisfaction, and commitment from the employees and as well as a supportive work climate was seen.

A growing number of scholars have explored the positive impacts of having PsyCap in the Chinese context. For instance, Luthans et al. (2005) invested the PsyCap of 422 Chinese participants working in either private or state-owned companies. Results showed that hope, optimism and resiliency (separately and in combination) were positively related to their performance as rated by their supervisors. Moreover, the variables were positively related to their performance outcome of relative meritbased salary. Luthans et al. (2008a) showed similar results. Wang et al. (2012a,b) showed that PsyCap helped Chinese nurses and doctors to fight against their work burnout. Cheung et al. (2011) applied PsyCap to investigate 264 full time Chinese school teachers in Mainland China. Results showed that when teachers had high PsyCap, they had higher job satisfaction and lower work burnout. In addition, the positive association between deep acting and job satisfaction was further reinforced among participants with high PsyCap.

\section{Predictors of Psychological Capital}

It was noted that the previous studies focused merely on the significant impact of PsyCap in the work situation. However, limited studies focused on the potential predictors of PsyCap (Avey, 2014). The current study tried to fill this research gap by examining variables in the cognitive and affective aspects that might predict the four variables of PsyCap, namely efficacy, hope, optimism and resiliency, as suggested by Luthans et al. (2007b), of a large group of Chinese teachers in Mainland China. Luthans et al. (2007a) included two variables (creativity and wisdom) in the cognitive aspect and three variables (well-being, flow, and humor) in the affective aspect. Creativity, wisdom, well-being, flow, and humor were only considered to be potentially related to PsyCap because these positive constructs were found to be "highly promising in terms of both their theoretical foundations and potential applicability to the workplace" (Luthans et al., 2007b, p. 145). Workplace was mentioned because it was stated earlier that PsyCap has been emphasized by the business field and it was found to be related to employees' performance, satisfaction, and commitment. The above potential positive constructs must be applicable to the business or workplace environment. However, these potential positive constructs have not yet been empirically tested by Luthans et al. (2007b) to see if they were really related to PsyCap significantly.

\section{Cognitive Aspect: Growth Mindset and PsyCap}

Mindset, also named as implicit theories, is defined as basic belief toward the malleability of personal qualities (Dweck et al., 1995; Yeager and Dweck, 2012). An individual with a growth mindset, named as incremental theory, believe that one's basic qualities such as intelligence can be developed if s/he put efforts into practice. On the other hand, an individual with a fixed mindset, namely entity theory, believe that one's basic qualities cannot be altered and are static (Dweck, 2009; Yeager and Dweck, 2012). Previous research demonstrated that growth mindset could contribute to the improvement of work engagement among employees in organizational environments (Heslin, 2010; Keating and Heslin, 2015) as well as teachers and students in school settings (Blackwell et al., 2007; Zeng et al., 2016, 2019). This is because people who viewed intelligence as malleable quality, instead of static and fixed one, would have more positive beliefs about efforts, be more engaged in their work, and persist longer when faced setbacks and difficulties (Blackwell et al., 2007). To the best of our knowledge, there is no direct evidence examining the association between growth mindset and psychological capital, although there is much evidence showing that growth mindset is closely related with the constituents of PsyCap as shown below.

One of the major dimensions of PsyCap is resilience, defined as "the capacity to rebound or bounce back from adversity, conflict, failure or even positive events, progress and increased responsibility" (Luthans, 2002, p. 702). Research demonstrated that growth mindset could predict resilience (e.g., Dweck, 2010; Zeng et al., 2016). For example, students who hold growth mindset have a higher level of resilience when faced with setbacks and difficulties compared with fixed mindset students (Dweck, 2010). Zeng et al. (2016) found that growth mindset predicted 
resilience and was related to higher school engagement and well-being in Chinese students. Previous studies also found that growth mindset could increase individual's resilient level because it changed people's view toward setbacks, efforts and challenges, and promoted learning strategies as well (Yeager and Dweck, 2012; Burnette et al., 2013). Individuals with growth mindset comprehend the challenges they faced as precious opportunities to enhance their basic qualities as well as improve their learning skills, which contribute to their resilience levels (Hong et al., 1999; Blackwell et al., 2007; Nussbaum and Dweck, 2008).

Another major dimension of PsyCap is hope. Based on Snyder's hope theory 2000, hope is composed of pathway thinking and agency thinking toward goals (Snyder et al., 1991). People with high levels of hope could find alternatives methods of overcoming and addressing their obstacles (Lee and Park, 2016). Growth mindset people tend to focus on the meaningful learning (Abrami and McWhaw, 2001), therefore they are more likely to apply various methods and persist efforts toward their goals with high levels of hope.

Self-efficacy is another important dimension of PsyCap. PsyCap efficacy is the beliefs about one's abilities to successfully achieve a particular objective (Luthans, 2002). Research found that growth mindset and self-efficacy are positively associated. For example, Strosher (2003) demonstrated the impacts of incremental implicit theory in teachers on their sense of selfefficacy in classroom.

Based on what discussed above, we expect that growth mindset, as a cognitive variable, could be a potential predictor of PsyCap. However, little direct evidence demonstrating that growth mindset could contribute to the PsyCap. To fill this blank, this study aims to investigate whether growth mindset could influence PsyCap positively and explore its underlying mechanism.

\section{Affective Aspect: Well-Being and PsyCap}

Research has shown that well-being is closely associated with PsyCap as well as multiple constituent elements of PsyCap (e.g., Luthans et al., 2007a; Culbertson et al., 2010). In terms of well-being, Luthans et al. (2007b) proposed it as an important psychological strength and capacity of the workplace and it is defined as "one's perceptions and feelings of emotional wellbeing (positive and negative affect, life satisfaction, and happiness), psychological well-being (self-acceptance, personal growth, purpose in life, environmental mastery, autonomy, and positive relations with others), and social well-being (social acceptance, actualization, contribution, coherence, and integration)" (p. 158). Luthans et al. (2007b) also suggested that flow could be associated with PsyCap, it was stated that "like SWB, flow is closely related to happiness and optimal experience" (p. 160). Many studies have examined that relationship between well-being and flow experience and found that they were significantly related (Fritz and Avsec, 2007; Heo et al., 2010; Carpentier et al., 2012). Additionally, study demonstrated that a composite operationalization of PsyCap was positively related with job satisfaction (Luthans et al., 2007a).

Previous studies also shown that well-being is closely linked with the various constituents of PsyCap, including efficacy, optimism, hope, and resiliency. For instance, PsyCap efficacy is based on Bandura (1997) theory, concerning beliefs about one's abilities to successfully achieve a particular objective or perform a valuable task. Highly efficacious individuals are less influenced by self-doubt, negative feedbacks, setbacks, and criticism (Bandura and Locke, 2003). Therefore, PsyCap efficacy is closely related with well-being and happiness (Culbertson et al., 2010). The second constituent of PsyCap is optimism, which originated from Seligman (1998) work and defined as individual's positive attributional style about success. Previous research on optimism has shown a positive relationship between mental well-being (Scheier and Carver, 1992) and life satisfaction (Seligman, 2002). The third dimension of PsyCap is hope. Similar to optimism, studies have demonstrated that hope was closely linked with subjective well-being (e.g., Kato and Snyder, 2005). The last constituent of PsyCap is resilience. There is empirical evidence in the literature found that resilience is associated with positive impacts on well-being at workplace. For instance, Maddi (1987) found that there is a positive relationship between resilience and happiness among employees undergoing downsizing. Moreover, previous research demonstrated positive relations between PsyCap resiliency and job satisfaction (Larson and Luthans, 2006) and happiness (Youssef and Luthans, 2007) as well. Based on previous studies, we expect that well-being, as a affective variable, could possibly serve as a predictor of PsyCap.

Taken all together, the current study examined growth mindset and well-being as potential predictors of PsyCap in a group of Chinese primary school teachers in China. The review of the previous research has led us to the conceptual model presented in Figure 1.

\section{AIMS OF THE PRESENT STUDY}

This study investigated the predictors of the PsyCap (namely efficacy, hope, optimism and resiliency) of a large group of Chinese primary school teachers working in China. As mentioned by Avey (2014), research on finding out the variables for predicting PsyCap was limited and research also showed that having strong PsyCap was important for individuals' work situation. Therefore, based on the framework of Luthans et al. (2007b), this study applied the variables from the cognitive (growth mindset) and affective (well-being) aspects in predicting primary Chinese teachers' PsyCap. The research questions of this study included the following:

(1) Does growth mindset predict the variables in the PsyCap of primary school Chinese teachers?

(2) Does well-being predict the variables in the PsyCap of primary school Chinese teachers?

\section{METHODS}

\section{Participants}

One thousand three hundred and eighty-four in-service teachers were recruited from Chengdu city, in southwestern China. Participants completed the survey, response rate is $93 \%$. In this sample, their age ranges from 20 to 58 (Mean age $=34.35$, $\mathrm{SD}=8.45$ ); there were 1,195 females and 189 males. 


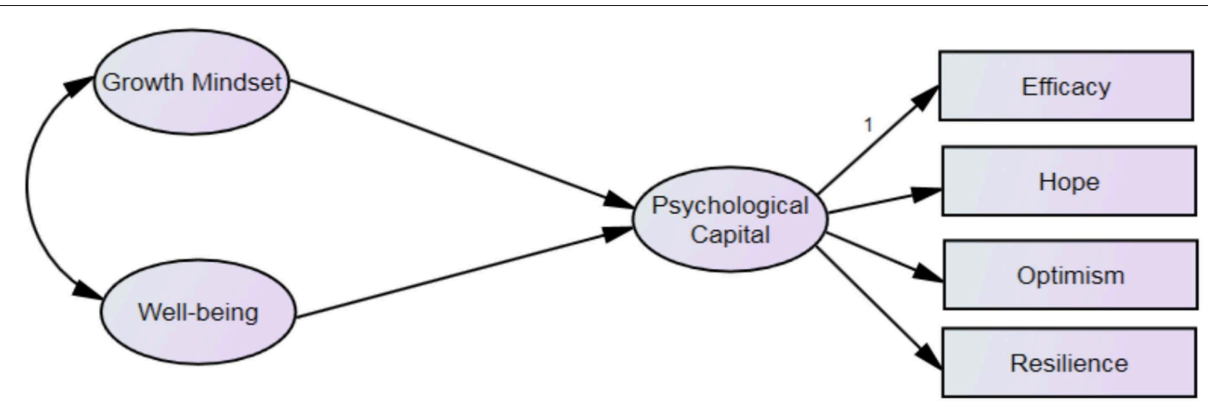

FIGURE 1 | A conceptual model.

\section{Procedures}

A number of middle schools in Southern China volunteered to participate in the current research project. Participants in this research project were informed about the objectives of the current study. They assured that their information and responses to questionnaires would be kept confidential and be only accessible to researchers for research purposes. Before administering the survey, written consent was obtained from participants. The research procedure was approved by the Human Research Ethics Committee at Tsinghua University. The teachers of the participated schools completed the online questionnaires in 3 days.

\section{Measures}

\section{Psychological Capital}

The 24-item measure of psychological capital (PCQ) was used and it was original developed by Luthans et al. (2007a), and has been examined in the Chinese sample (Luthans et al., 2005). Respondents had to rate themselves on a six-point Liker scale ( 1 = strongly disagree, $6=$ strongly agree $)$. Here are some sample items: (a) efficacy: "I feel confident in representing my work area in meetings with management"; (b) hope: "If I should find myself in a jam at work, I could think of many ways to get out of it"; (c) resilience: "I usually take stressful things at work in stride"; and (d) optimism: "I always look on the bright side of things regarding my job". PCQ demonstrates good construct and criterion-related validity, with average Cronbach's alpha of 0.89 across four samples (Luthans et al., 2007a). In the present study, Cronbach's alpha for the whole scale was 0.97 .

\section{Growth Mindset}

For the cognitive aspect, the four-item growth mindset inventory (Dweck, 2006) was employed to measure the degree of the growth mindset of respondents. Participants answered the questions by items using a six-point Likert scale from $1=$ (strongly disagree) to $5=($ strongly agree $)$. The measure has strong internal consistency, with test-retest reliability for this measure over a 2-week period was 0.77 (Blackwell et al., 2007). Example item is such "You can always substantially change how intelligent you are." In this study, Cronbach's alpha for the growth mindset subscale was 0.74 .

\section{Well-Being}

In terms of the affective aspect of well-being, the overall wellbeing consisted of five factors: positive emotion, engagement, relationship, meaning, and accomplishment (PERMA) (Seligman, 2011). PERMA profile (Butler and Kern, 2016) was used to measure theses five dimensions of well-being. Respondents rated themselves on a ten-point Likert from scale $0=($ never $/$ very bad $)$ to $10=($ always $/$ very good $)$. Example item is such "In general, how often do you feel joyful?" (positive emotion); "How often do you become absorbed in what you are doing?"(engagement); "To what extent do you receive help and support from others when you need it?"(relationship); "In general, to what extent do you lead a purposeful and meaningful life?" (meaning); "How often do you achieve the important goals you have set for yourself?"(accomplishment) PERMA has shown evidence for convergent and divergent validity, acceptable reliability, and cross-time stability (Butler and Kern, 2016). In this study, Cronbach's alpha for the whole scale was 0.95 .

\section{RESULTS}

\section{Descriptive and Preliminary Analysis}

As shown in Table 1, the mean values of all the variables (PsyCap, growth mindset and well-being) were all on the higher side of the scale. As demonstrated in Table 1, all these variables were significantly correlated in the expected manner. PsyCap was positively and strongly correlated with both growth mindset $(r=0.61, p<0.01)$ and well-being $(r=0.69, p<0.01)$. Although more female participants are involved in this study, results from both correlational and $t$-test analysis (see Table 2 ) suggested that there were no significant differences on all the study variables (psychological capital, growth mindset and well-being) across gender groups.

\section{Structural Equation Modeling}

Using AMOS structural equation modeling software, we developed an initial model where growth mindset and well-being predict PsyCap, as seen in Figure $\mathbf{1}$ above. Next, we conducted a series of path analysis based on our initial model. In the level of measurement models, all the loadings were shown significantly, ranged from 0.59 to 0.93 , suggesting that all the observed indicators could be reasonably explained by the latent variables. 
TABLE 1 | Descriptive analysis and correlations between all variables $(n=1,384)$

\begin{tabular}{lcccc}
\hline Measures & $\mathbf{1}$ & $\mathbf{2}$ & $\mathbf{3}$ & $\mathbf{4}$ \\
\hline 1. Psychological capital & - & & & \\
2. Growth mindset & $0.61^{\star \star}$ & - & & \\
3. Well-being & $0.69^{\star \star}$ & $0.49^{\star \star}$ & - & \\
4. Gender $(1=$ male, $2=$ female) & 0.01 & -0.04 & 0.05 & - \\
Range & $1-6$ & $1-5$ & $0-10$ & $1-2$ \\
$M$ & 4.35 & 3.33 & 6.47 & $\mathrm{~N} / \mathrm{A}$ \\
SD & 0.76 & 0.61 & 1.56 & $\mathrm{~N} / \mathrm{A}$ \\
\hline
\end{tabular}

${ }^{*} p<0.05 ;{ }^{* *} p<0.01$

TABLE 2 | Gender difference between all variables $(n=1,384)$.

\begin{tabular}{|c|c|c|c|c|c|c|}
\hline \multirow[t]{2}{*}{ Variables } & \multirow{2}{*}{$\begin{array}{c}\text { Male } \\
(N=189) \\
\text { Mean }\end{array}$} & \multicolumn{3}{|c|}{$\begin{array}{c}\text { Female } \\
(N=1,195)\end{array}$} & \multirow[t]{2}{*}{$t$-value } & \multirow[t]{2}{*}{$p$-value } \\
\hline & & $S D$ & Mean & $S D$ & & \\
\hline Psychological capital & 4.32 & 0.82 & 4.35 & 0.74 & -0.48 & 0.63 \\
\hline Growth mindset & 3.38 & 0.68 & 3.32 & 0.60 & 1.18 & 0.24 \\
\hline Well-being & 6.28 & 1.75 & 6.51 & 1.52 & -1.70 & 0.06 \\
\hline
\end{tabular}

${ }^{*} p<0.05 ;{ }^{* *} p<0.01 ;{ }^{* \star *} p<0.001$.

In terms of measurement model, we referred to the comparative fit index (CFI), the Tucker-Lewis index (TLI), Standardized Root Mean Square Residual (SRMR) and the root mean square error of approximation (RMSEA). CFI and TLI values $>0.90$ are considered to indicate acceptable model fit, SRMR and RMSEA values at or below 0.08 indicate that the model provides a reasonable fit to the data (Byrne, 2016). In this study, when we estimate the measurement and path model simultaneously, the resulting fit indices for this mode were: $\chi 2(62)=483.026$, $p<0.001, \mathrm{CFI}=0.97$, TLI $=0.96$, SRMR $=0.03$, $\mathrm{RMSEA}=0.07$, indicating a satisfactory fit to the data (see Figure 2).

As shown in Figure 2, all proposed paths were significant at the 0.01 level of better. The paths from growth mindset to PsyCap $(\beta=0.44, p<0.001)$, the path from well-being to PsyCap $(\beta=0.49, p<0.001)$, and the covariant path between growth mindset and well-being $(\beta=0.58, p<0.001)$, were all significant and positive.

In conclusion, these results supported our conceptual model, indicating that both growth mindset (cognitive component) and well-being (affective component) could significantly and positively predict PsyCap among primary school teachers in China. In other words, primary school teachers with higher levels of growth mindset and well-being tended to have greater PsyCap.

\section{DISCUSSION AND IMPLICATIONS}

Based on the results of this study, both the variables of growth mindset and well-being were able to significantly and positively predict the four variables of PsyCap, namely efficacy, hope, optimism, and resiliency of a large group of Chinese primary school teachers teaching in Mainland China.

\section{Explanation of Growth Mindset as a Predictor}

Results of this study demonstrated that when Chinese primary school teachers held a growth mindset were found to have higher PsyCap. To the best of our knowledge, this is the first study to examine the relationships between growth mindset and PsyCap. The current findings are consistent with and extend the previous study findings, which showed that growth mindset is positively correlated with some constituents of PsyCap (e.g., Dweck, 2010; Zeng et al., 2016).

First, our study found that growth mindset and self-efficacy are positively associated; this is consistent with previous literature (Strosher, 2003). Sweetman et al. (2010) have explained that efficacy is basically the self-belief of what the person can do with his or her own skills, and it is considered as a generative capability that influences performance through the application of inventiveness and resourcefulness (Bandura, 1986). In other words, higher inventiveness may lead a person to rate himself as being more capable. While facing the failure, instead of merely experiencing the negative emotional state and attributing the failure to their lack of ability, people with growth mindset tend to interpret the failure as a learning process and as a chance to growth. They will try to look for positive strategies and alternative solution; this could help maintain one's confidence of their perceived ability and positive self-image. All these above could explain why higher teachers having growth mindset could positively predict higher efficacy in this study.

In terms of hope, Sweetman et al. (2010) stated that when individuals have high hope, they "not only have the willpower and motivation but also have the ability to determine a pathway to achieve their goal and are able to generate multiple pathways and adapt their plans as needed" (p. 6). Individuals with high hope will think of different methods to achieve their plans and goals, and growth mindset is needed for them to determine their pathway and initiate more internal motivation to achieve their goal. When individuals have growth mindset, they can think flexibly of more strategies for attaining their destination and leading them to have higher hope. Overall, people with growth mindset can potentially predict higher hope and efficacy.

As discussed in the study by Rego et al. (2012), optimists always view things from the positive side and thus they experience less depression, guilt, self-blame and despair. Moreover, they are less likely to give up when they face obstacles and challenges because they always have a positive outlook and can "look for creative ways to solve problems and take advantage of opportunities" (p. 431). Therefore, it is understandable that people with a growth mindset, are more easily to focus on the meaning behind and keep persistent. This can provide them with more sustainable agency and different creative methods of solving problems and this can help them sustain and enhance their optimism.

For the relationship between resiliency and growth mindset, Rego et al. (2012) mentioned that during difficult times, individuals with high resiliency are able to overcome, bounce back and then research out to pursue new knowledge and experiences in order to find deeper meaning with others and in 


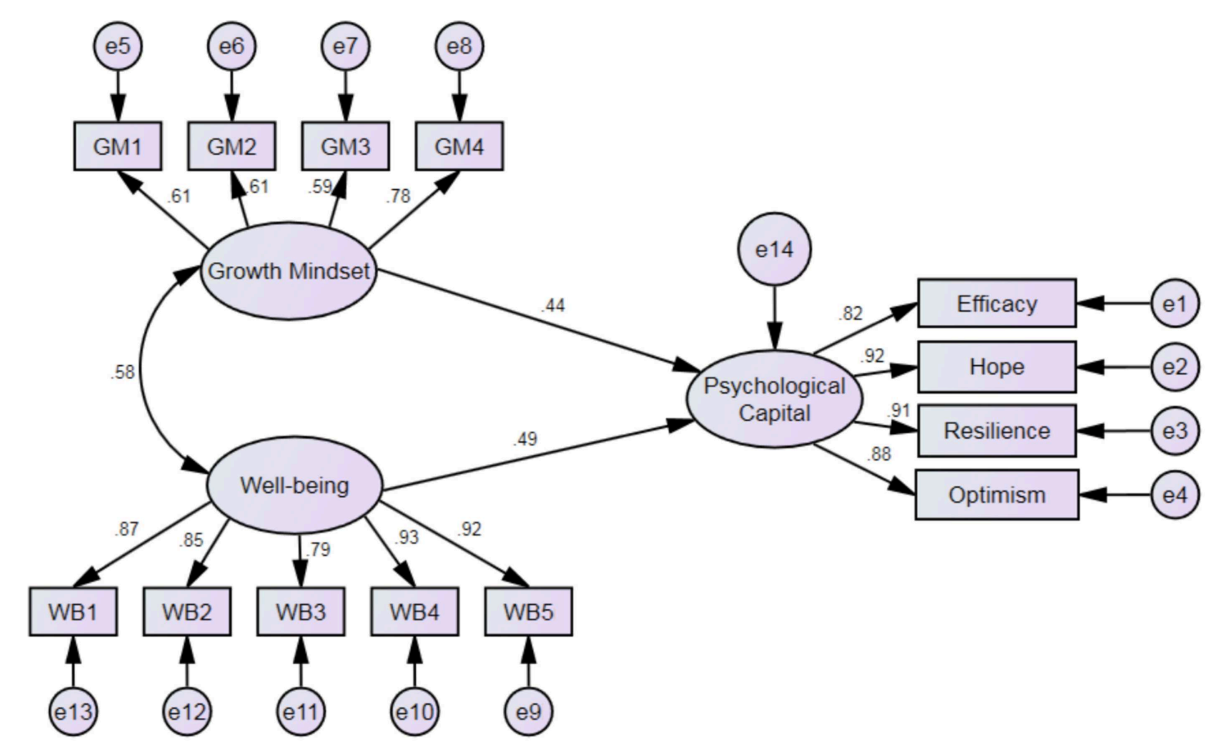

FIGURE 2 | Standardized estimated results of SEM for growth mindset, well-being and psychological capital $(n=1,384)$.

life. Some studies also showed people are curious and are willing to open themselves to new experiences are found to be more resilient. This may be because their creativity or growth mindset can help them develop new ways of doing things in order to strive through difficult times and failures (Tugade et al., 2004; Youssef and Luthans, 2007). The relationship between growth mindset and the PsyCap variables of optimism and resiliency are found to be associated positively. The results of the above studies could plausible explain on why Chinese primary school teachers who had a higher growth mindset would also have higher PsyCap (efficacy, hope, optimism and resiliency). As suggested by O'Brain (2012), it is important to foster teachers to have a growth or an open mindset, because growth mindset might allow teachers to think differently and to avoid the traditional ways of thinking and the activation of typical associations in their teaching class; this may facilitate creative teaching and learning in the classroom.

\section{Explanation of Well-Being as a Predictor}

Similar to Youssef-Morgan and Luthans (2015), our results demonstrated that well-being was able to predict PsyCap of Chinese primary school teachers. One possible explanation is that for individuals to have overall well-being, they should rate themselves highly in the following variableswork PsyCap (including job satisfaction and objective work outcomes), relationship PsyCap (including relationship satisfaction and objective relationship outcomes), and health PsyCap (including health satisfaction and objective health outcomes) (Luthans et al., 2013). Then, when individuals have high overall well-being, they will have high overall PsyCap as the outcome (high efficacy, hope, optimism, and resiliency).

The formation of well-being is the result of positive cognitive and affective self-appraisals of life of specific life domains, events and circumstances related to, for example, their work, relationship and health (Youssef-Morgan and Luthans, 2015). Moreover, Sui et al. (2015) explained that well-being is a positive emotion and positive emotions are able to "broaden people's attention and thinking, enabling individuals to draw flexibly on higher level connections and wider-than-usual ranges of percepts and ideas. In turn, these broadened and flexible outlooks help people to discover and build survival-promoting personal resources" (Fredrickson and Kurtz, 2011, p. 35). One of the personal resources is psychological resource and the four variables found in PsyCap could be considered as variables in the psychological resources of individuals.

The present results suggest two important factors that could contribute in enhancing teachers' PsyCap: growth mindset and well-being. In the educational practice, schools should provide more support for teachers to enhance their growth mindset and well-being. In terms of growth mindset, schools could form a discussion group for teachers to share their fixed or growth mindset thoughts regularly. Later, based on their feedbacks, researchers and counselors could help to provide teachers the necessary pre-service or in-service professional and developmental training, such as transformative mindsets and mental health development. In terms of well-being, school could offer teachers with more financial and psychological support. For example, for teachers who are in low SES, or have relatively low educational background, it is important for schools to provide them with more additional career training opportunities and financial aid program, such as organizing career development workshop, setting up the continuing education fund. In turn, teachers with more PsyCap are likely to perceive better job satisfaction, and do better in dealing with work-related difficulties and challenges. As a result, it could help schools to create a more positive teaching and learning environment for students. 


\section{CONCLUSION AND LIMITATION}

This study had some limitations. First of all, the current study demonstrated that growth mindset and well-being are two predictors of PsyCap. However, there are other possible variables that might be considered as predictors of PsyCap. For example, Luthans et al. (2007b) suggested creativity, wisdom, well-being, flow and humor are five potential positive constructs from the cognitive and affective aspects. A clear picture could be seen if the study included more predictors of PsyCap, therefore, future studies may consider including the rest variables for testing their relationships with PsyCap. Second, there were a lot more female teachers than male teachers. Generally speaking, primary schools around the world hired more female teachers than male teachers. Unfortunately, it is difficult to overcome this limitation. Thirdly, the common method bias of self-report questionnaire needs to be considered. Future studies should include more measurements tools, such as objective measurements. Lastly, this study employed a cross-sectional design study, to examine the associations between the variables; therefore, we can not make causal inference. Future studies could explore the causal relationships between variables by utilizing experimental and longitudinal studies.

Overall, this study investigated the relationship among growth mindset, well-being and the PsyCap of 1,384 Chinese primary school teachers in Mainland China. Results showed that

\section{REFERENCES}

Abrami, K., and McWhaw, P. C. (2001). Student goal orientation and interest: effects on students' use of self-regulated learning strategies. Contemp. Educ. Psychol. 26, 311-329. doi: 10.1006/ceps. 2000.1054

Avey, J. B. (2014). The left side of psychological capital. J. Leader. Organ. Stud. 21, 141-149. doi: 10.1177/1548051813515516

Avey, J. B., Reichard, R. J., Luthans, F., and Mhatre, K. H. (2011). Meta-analysis of the impact of positive psychological capital on employee attitudes, behaviors, and performance. Hum. Resour. Dev. Q. 22, 127-152. doi: 10.1002/hrdq.20070

Bandura, A. (1986). Social Foundations of Thought and Action. Englewood Cliffs, NJ: Prentice Hall.

Bandura, A. (1997). Self-efficacy: The Exercise of Control. New York, NY: Freeman. Bandura, A., and Locke, E. (2003). Negative self-efficacy and goal effects revisited. J. Appl. Psychol. 88, 87-99. doi: 10.1037/0021-9010.88.1.87

Blackwell, L. S., Trzesniewski, K. H., and Dweck, C. S. (2007). Implicit theories of intelligence predict achievement across an adolescent transition: a longitudinal study and an intervention. Child Dev. 78, 246-263. doi: 10.1111/j.1467-8624.2007.00995.x

Burnette, J. L., O’Boyle, E. H., VanEpps, E. M., Pollack, J. M., and Finkel, E. J. (2013). Mind-sets matter: a meta-analytic review of implicit theories and self-regulation. Psychol. Bull. 139, 655-671. doi: 10.1037/a0029531

Butler, J., and Kern, M. L. (2016). The PERMA-profiler: a brief multidimensional measure of flourishing. Int. J. Wellbeing 6, 1-48. doi: 10.5502/ijw. v6i3.526

Byrne, B. M. (2016). Structural Equation Modeling With AMOS: Basic Concepts, Applications, and Programming. New York, NY: Routledge.

Carpentier, J., Mageau, G. A., and Vallerand, R. J. (2012). Remination and flow: why do people with a more harmonious passion experience higher well-being? J. Happi. Stud. 13, 501-518. doi: 10.1007/s10902-011-9276-4

Cassidy, T., McLaughlin, M., and McDowell, E. (2014). Bullying and health at work: the mediating roles of psychological capital and social support. Work Stress 28, 255-269. doi: 10.1080/02678373.2014.927020 growth mindset and well-being were able to significantly and positively predict teachers' PsyCap in general. As mentioned at the beginning of this paper, previous studies focused mainly on the outcomes of having high PsyCap on employees from the business field, limited empirical studies investigated the predictors of the formation of PsyCap, especially in the educational setting. Referring to results of this study and based on the framework of Luthans et al. (2007b), it is necessary to increase the growth mindset (cognitive aspect) and the wellbeing (affective aspect) of teachers in order for them to increase their PsyCap.

\section{ETHICS STATEMENT}

All participants were informed about the objectives of the study and assured that all responses would be kept confidential, only accessible to the research group and used for research purposes. Before administering the survey, written consent was obtained from participants. All procedures were approved by the Human Research Ethics Committee at Tsinghua University.

\section{AUTHOR CONTRIBUTIONS}

$\mathrm{XC}$ designed the research and drafted part of the manuscript. GZ collected the data, drafted part of the manuscript and make revision. EC and HC drafted part of the manuscript.

Chan, D. W. (2003). Hardiness and its role in the stress-burnout relationship among prospective Chinese teachers in Hong Kong. Teach. Teacher Educ. 19, 381-395. doi: 10.1016/S0742-051X(03)00023-4

Cheung, F., Tang, C. S., and Tang, S. (2011). Psychological capital as a moderator between emotional labor, burnout, and job satisfaction among school teachers in China. Int. J. Stress Manage. 18, 348-371. doi: 10.1037/a0025787

Culbertson, S. S., Fullagar, C. J., and Mills, M. J. (2010). Feeling good and doing great: the relationship between psychological capital and well-being. J. Occup. Health Psychol. 15, 421-433. doi: 10.1037/a0020720

Dweck, C. S. (2006). Mindset: The New Psychology of Success. New York, NY: Random House Incorporated.

Dweck, C. S. (2009). Who will the 21st-century learners be? Knowledge Quest 38, $8-9$.

Dweck, C. S. (2010). Mind-sets. Principal Leadership 10, 26-29.

Dweck, C. S., Chiu, C., and Hong, Y. (1995). Implicit theories and their role in judgments and reactions: a word from two perspectives. Psychol. Inquiry 6, 267-285. doi: 10.1207/s15327965pli0604_1

Fredrickson, B. L., and Kurtz, L. E. (2011). "Cultivating positive emotions to enhance human flourishing," in Applied Positive Psychology: Improving Everyday Life, Health, Schools, and Society, S. I. Donaldson, M. Csikszentmihalyi, and J. Nakamura (New York, NY; Hove: Psychology Press), 35-47.

Fritz, B. S., and Avsec, A. (2007). The experience of flow and subjective well-being of music students. Horiz. Psychol. 16, 5-17.

Heo, J., Lee, Y., McCormick, B. P., and Pedersen, P. M. (2010). Daily experience of serious leisure, flow and subjective well-being of older adults. Leisure Stud. 29, 207-225. doi: 10.1080/02614360903434092

Heslin, P. A. (2010). "Mindsets and employee engagement: theoretical linkages and practical interventions," in Handbook of Employee Engagement: Perspectives, Issues, Research and Practice, ed S. L. Albiect (Cheltenham: Edward Elgar), 218-226.

Hong, Y. Y., Chiu, C. Y., Dweck, C. S., Lin, D. M. S., and Wan, W. (1999). Implicit theories, attributions, and coping: a meaning system approach. J. Pers. Soc. Psychol. 77, 588-599. doi: 10.1037/0022-3514.77.3.588 
Kato, T., and Snyder, C. R. (2005). The relationship between hope and subjective well-being: reliability and validity of the dispositional hope scale, Japanese version. Jpn. J. Psychol. 76, 227-234. doi: 10.4992/jjpsy.76.227

Keating, L. A., and Heslin, P. A. (2015). The potential role of mindsets in unleashing employee engagement. Resour. Manage. Rev. 25, 329-341. doi: 10.1016/j.hrmr.2015.01.008

Larson, M., and Luthans, F. (2006). Potential added value of psychological capital in predicting work attitudes. J. Leader. Organ. Stud. 13, 44-61. doi: 10.1177/10717919070130020601

Lee, C. S., and Park, J. Y. (2016). The effects of acculturative and family-related stress on the well-being of immigrant women in Korea: the mediating effect of hope. Indian J. Sci. Technol. 9, 1-7. doi: 10.17485/ijst/2016/v9i26/97281

Luthans, F. (2002). Positive organizational behavior: developing and managing psychological strengths. Acad. Manage. Execut. 16, 57-72. doi: 10.5465/ame.2002.6640181

Luthans, F., Avey, J. B., Avolio, B. J., Norman, S. M., and Combs, G. M. (2006). Psychological capital development: toward a micro-intervention. J. Organ. Behav. 27, 387-393. doi: 10.1002/job.373

Luthans, F., Avey, J. B., Clapp-Smith, R., and Li, W. (2008a). More evidence on the value of Chinese workers' psychological capital: a potentially unlimited competitive resources. Int. J. Hum. Resource Manage. 19, 818-827. doi: 10.1080/09585190801991194

Luthans, F., Avolio, B. J., Avey, J. B., and Norman, S. M. (2007a). Positive psychological capital: measurement and relationship with performance and satisfaction. Pers. Psychol. 60, 541-572. doi: 10.1111/j.1744-6570.2007.00083.x

Luthans, F., Avolio, B. J., Walumbwa, F. O., and Li, W. (2005). The psychological capital of Chinese workers: exploring the relationship with performance. Manage. Organ. Rev. 1, 249-271. doi: 10.1111/j.1740-8784.2005.00011.x

Luthans, F., Luthans, K. W., and Luthans, B. C. (2004). Positive psychological capital: beyond human and social capital. Business Horiz. 47, 45-50. doi: 10.1016/j.bushor.2003.11.007

Luthans, F., Norman, S. M., Avolio, B. J., and Avey, J. B. (2008b). The mediating role of psychological capital in the supportive organizational climate - employee performance relationship. Contexts Positive Organ. Behav. 29, 219-238. doi: 10.1002/job.507

Luthans, F., and Youssef, C. M. (2004). Human, social, and new positive psychological capital management: investing in people for competitive advantage. Organ. Dyn. 33, 143-160. doi: 10.1016/j.orgdyn.2004.01.003

Luthans, F., Youssef, C. M., and Avolio, B. J. (2007b). Psychological Capital: Developing the Human Competitive Edge. N.Y.: Oxford University Press.

Luthans, F., Youssef, C. M., Sweetman, D., and Harms, P. (2013). Meeting the leadership challenge of employee well-being through relationship PsyCap and health PsyCap. J. Leader. Organ. Stud. 20, 114-129. doi: $10.1177 / 1548051812465893$

Maddi, S. R. (1987). "Hardiness training at Illinois Bell Telephone," in Health Promotion Evaluation, ed. P. Opatz (Stevens Point, WI: National Well-ness Institute), 101-115.

Nussbaum, A. D., and Dweck, C. S. (2008). Defensiveness versus remediation: selftheories and modes of self-esteem maintenance. Pers. Soc. Psychol. Bull. 34, 599-612. doi: 10.1177/0146167207312960

O'Brain, M. (2012). Fostering a creativity mindset for teaching (and learning). Learning Landscape 6, 315-334. doi: 10.1002/ibd.21832

Rego, A., Sousa, F., Marques, C., and Cunha, M. P. E. (2012). Authentic leadership promoting employees' psychological capital and creativity. J. Business Res. 65, 429-437. doi: 10.1016/j.jbusres.2011.10.003

Scheier, M., and Carver, C. (1992). Effects of optimism on psychological and physical well-being: theoretical overview and empirical update. Cogn. Ther. Res. 16, 201-228. doi: 10.1007/BF01173489

Seligman, M. (1998). Learned Optimism. New York, NY: Pocket Books.

Seligman, M. (2002). Authentic Happiness. New York, NY: Free Press.
Seligman, M. E., and Csikszentmihalyi, M. (2000). Positive psychology: an introduction. Am. Psychol. Assoc. 55, 5-14. doi: 10.1037/0003-066X.55.1.5

Seligman, M. E. P. (2011). Flourish: A Visionary New Understanding of Happiness and Well-Being. New York, NY: Free Press.

Snyder, C. R. (ed) (2000). Handbook of Hope: Theory, Measures, and Applications. Academic Press.

Snyder, C. R., Irving, L. M., and Anderson, J. R. (1991). Hope and health. Handbook Soc. Clin. Psychol. Health Perspect. 162, 285-305.

Strosher, H. (2003). Prospective and practicing teachers' beliefs: a study of implicit theories of intelligence and teacher efficacy. Unpublished doctoral dissertation, University of Calgary, Alberta.

Sui, O. L., Cheung, F., and Lui, S. (2015). Linking positive emotions to work well-being and Turnover intention among Hong Kong police officers: the role of psychological capital. J. Happi. Stud. 16, 367-380. doi: 10.1007/s10902-014-9513-8

Sweetman, D. S, Luthans, F., Avey, J. B., and Luthans, B. C. (2010). Relationship between positive psychological capital and creative performance. Manage. Dep. Faculty Publ. 139, 4-13. doi: 10.1002/cjas.175

Tang, C. S. K., Au, W. T., Schwarzer, R., and Schmitz, G. (2001). Mental health outcomes of job stress among Chinese teachers: role of stress resource factors and burnout. J. Organ. Behav. 22, 887-901. doi: 10.1002/job.120

Tugade, M. M., Fredrickson, B. L., and Barrett, L. M. (2004). Psychological resilience and positive emotional granularity: examining the benefits of positive emotions on coping and health. J. Pers. 72, 1161-90. doi: 10.1111/j.1467-6494.2004.00294.x

Wang, Y., Chang, Y., Fu, J., and Wang, L. (2012a). Work-family conflict and burnout among Chinese female nurses: the mediating effect of psychological capital. BMC Public Health 12:915. doi: 10.1186/1471-2458-12-915

Wang, Y., Liu, L., Wang, J., and Wang, L. (2012b). Work-family conflict and burnout among Chinese doctors: the mediating role of psychological capital. J. Occup. Health 54, 232-240. doi: 10.1539/joh.11-0243-OA

Yeager, D. S., and Dweck, C. S. (2012). Mindsets that promote resilience: when students believe that personal characteristics can be developed. Educ. Psychol. 47, 302-314. doi: 10.1080/00461520.2012.722805

Youssef, C. M., and Luthans, F. (2007). Positive organizational behavior in the workplace: the impact of hope, optimism and resiliency. J. Manage. 33, 774-800. doi: 10.1177/0149206307305562

Youssef-Morgan, C. M., and Luthans, F. (2015). Psychological and well-being. Stress Health 31, 180-188. doi: 10.1002/smi.2623

Zeng, G., Chen, X., Cheung, H. Y., and Peng, K. (2019). Teachers' growth mindset and work engagement in the Chinese educational context: wellbeing and perseverance of effort as mediators. Front. Psychol. 10:839. doi: 10.3389/fpsyg.2019.00839

Zeng, G., Hou, H., and Peng, K. (2016). Effect of growth mindset on school engagement and psychological well-being of Chinese primary and middle school students: the mediating role of resilience. Front. Psychol. 7:1873. doi: 10.3389/fpsyg.2016. 01873

Conflict of Interest Statement: The authors declare that the research was conducted in the absence of any commercial or financial relationships that could be construed as a potential conflict of interest.

Copyright (c) 2019 Chen, Zeng, Chang and Cheung. This is an open-access article distributed under the terms of the Creative Commons Attribution License (CC BY). The use, distribution or reproduction in other forums is permitted, provided the original author(s) and the copyright owner(s) are credited and that the original publication in this journal is cited, in accordance with accepted academic practice. No use, distribution or reproduction is permitted which does not comply with these terms. 